\title{
Clinico- Biochemical Profile of Neonates with Birth Asphyxia in Eastern Nepal
}

\author{
Shah GS1 , Agrawal J², Mishra OP ${ }^{3}$ Chalise $\mathrm{S}^{4}$ \\ ${ }^{1}$ Dr. Gauri Shankar Shah, MBBS, MD, Professor and Head of Department, ${ }^{2}$ Dr. Jyoti Agrawal, MBBS, MD, Senior Resident, \\ ${ }^{3}$ Dr. Om Prakash Mishra, MBBS, MD, Professor (visiting), ${ }^{4}$ Dr. Shiva Chalise, MBBS, MD, Senior Resident. All from the \\ Department of Paediatrics, BP Koirala Institute of Health Sciences (BPKIHS), Dharan, Nepal.
}

Address for correspondence: Dr. Gauri S Shah, E-mail: gaurishankarshah@live.com

\begin{abstract}
Introduction: Perinatal asphyxia is a common problem with the incidence varying from $0.5-2 \%$ of live births. It is an important cause of neonatal mortality and is a frequent cause for admission to neonatal intensive care units (NICU). The aims of this study were to find out the clinical and biochemical alterations in different stages of HIE. Materials and Methods: This was a prospective hospital based observational study performed during the period of February, 2010 to January, 2011. Results: Sixty inborn neonates satisfying the criteria for birth asphyxia requiring admission to pediatric wards and neonatal intensive care unit were studied. There were $13(21.7 \%)$ cases of mild hypoxemic ischemic encephalopathy (HIE), 27 (45\%) moderate and 20 (33.3\%) severe HIE. Seizures 41(68.3\%), respiratory distress 32(53.3\%) and shock 29(48.3\%) were predominant manifestations observed. Meconium aspiration syndrome was found in $13.3 \%$ of neonates. Hypoglycemia $11(18.3 \%)$, hypocalcaemia $7(11.7 \%)$, hyponetremia $14(23.3 \%)$ and hyperbilirubinemia $9(15 \%)$ were associated biochemical abnormalities. Twenty cases (33.3\%) had acute renal failure and they belonged to moderate and severe stages of HIE. Seizures $(P<0.001)$, respiratory distress $(P=0.015)$, shock $(P<0.001)$ and serum creatinine $(P=0.004)$ were found to be significant among different HIE stages. Conclusion: Neonates having birth asphyxia had HIE, seizures, respiratory distress, shock, hypoglycemia hypocalcaemia, hyponetremia, hyperbilirubinemia and acute renal failure mostly in moderate and severe stages
\end{abstract}

Key words: Birth asphyxia, Acute renal failure, Seizures

\section{Introduction}

Perinatal asphyxia is a common problem with the incidence varying from $0.5-2 \%$ of live births ${ }^{1-4}$. It is an important cause of neonatal mortality and is a frequent cause for admission to neonatal intensive care units (NICU). According to World Health Organization (WHO), approximately 4 million babies die each year before they reach the age of one month. ${ }^{1,5,6}$ Ninety-eight percent of neonatal deaths take place in the developing countries. Perinatal asphyxia and birth injuries together contribute to almost $29 \%$ of deaths. Most of the births in Nepal occur at home $72 \%$, usually attended by untrained birth attendants, 64\% according to Nepal Demographic and Health survey (NDHS) 2011. Failure to initiate and sustain breathing immediately after delivery has been associated with hypoxic-ischemic injury to the central nervous system and the clinical manifestations of this injury have been termed as Hypoxic Ischemic Encephalopathy (HIE). $\mathrm{HIE}$ is of concern in an asphyxiated neonates because it can lead to serious long-term neuro-developmental sequelae among survivors ${ }^{7}$.

Perinatal asphyxia is defined as the presence of hypoxia, hypercapnia, and acidosis leading the newborn with systemic disturbances. ${ }^{8,9}$ When a neonate suffers asphyxia, series of cinical ${ }^{10}$ and biochemical ${ }^{11}$ alterations occur which can adversely affect the outcome' ${ }^{1}$. American Academy of Pediatrics (AAP) and American College of Obstetrics and Gynecology (ACOG) ${ }^{12}$ proposed the criteria for birth asphyxia: viz. profound metabolic or mixed acidemia, persistence of Apgar scores 0-3 for longer than 5 minutes, neonatal neurologic HIE (e.g.,seizures, coma, hypotonia) and multiple organs( of kidney, lungs, liver, heart, intestine) involvement.

In a developing country like Nepal, majority of deliveries takes place in rural area or during transport on the way to hospital and mostly unattended. As a result 
neonates often suffer birth asphyxia and brought to the hospital in moribund stage. As such outcome of birth asphyxia was reported a decade ago. ${ }^{13}$. However, with development of recent Neonatal Resuscitation Program (NRP) guidelines and better infrastructure facilities in present $\mathrm{NICU}$, there may be change in the course and outcome of these cases. Therefore, we present our observations on clinico- biochemical profile of neonates who suffered from birth asphyxia and its outcome.

\section{Materials and Methods}

This was a prospective hospital based observational study performed during the period of February, 2010 to January, 2011. The protocol of the study was approved by the Institute Ethics Committee and written informed consent was obtained from the parents of each neonate. Sixty inborn term neonates who suffered from birth asphyxia and progressed to HIE (as classified by Levene staging ${ }^{13}$ using consciousness, tone, seizures, sucking/ respiration)) were included in the study. Birth asphyxia was defined by Apgar score of $\leq 6$ at $1 \mathrm{~min}$. All neonates were resuscitated as per NRP guidelines ${ }^{12}$. Cases with positive septic screening and gross congenital malformations were excluded. Detailed history and general physical and systemic examinations were recorded in a pre-designed proforma.

The hematological parameters included hemoglobin, hematocrit, total leukocyte and differential counts, platelet count and micro ESR. Blood glucose, calcium, sodium, potassium, urea, creatinine, bilirubin and arterial blood gas monitoring were also performed. Blood glucose $<40 \mathrm{mg} / \mathrm{dl}$, serum ionized calcium less than $1 \mathrm{mmol} / \mathrm{L}$ and sodium < $135 \mathrm{meq} / \mathrm{L}$ was taken as hypoglycemia, hypocalcemia and hyponatremia. Repeat monitoring was done, if the parameter was abnormal on initial test, after taking corrective measures.

\section{Statistical analysis}

Differences in mean of quantitative data among birth asphyxia were compared by Analysis of Variance (ANOVA) and Kruskal Wallis and proportions by ChiSquare tests. A $p$ value of $<0.05$ was considered as statistically significant.

\section{Results}

Clinical and biochemical profile of neonates with birth asphyxia are presented in Table 1 and 2. According to HIE staging, $13(21.7 \%)$ were in mild, 27(45\%) in moderate and 20 (33.3\%) belonged to severe HIE group. Seizures were present in $68.3 \%$; majority of subtle variety (75.6\%). Respiratory distress, shock and congestive heart failure were found in $53.3 \%, 48.3 \%$ and $1.7 \%$ of cases, respectively. Features of meconium aspiration syndrome were seen in $13.3 \%$ and raised intracranial pressure in the form of full anterior fontanel in $10 \%$ neonates. Three (5\%) neonates developed hypothermia. Hypoglycemia $11(18.3 \%)$, hypocalcaemia $7(11.7 \%)$, hyponatremia $14(23.3 \%)$ and hyperbilirubinemia in 9(15\%) were associated biochemical features. Twenty cases (33.3\%) had acute renal failure and oliguria was present in $14(23.3 \%)$ cases even after 72 hour of post natal life.

Table1: Clinical profile of neonates with birth asphyxia

\begin{tabular}{|l|c|c|c|}
\hline Clinical details & Categories & $\mathbf{n}$ & $\%$ \\
\hline \multirow{3}{*}{ HIE staging } & 1 & 13 & 21.7 \\
\cline { 2 - 4 } & 2 & 27 & 45.0 \\
\cline { 2 - 4 } & 3 & 20 & 33.3 \\
\hline \multirow{3}{*}{ Types of seizures } & Subtle & 31 & 75.6 \\
\cline { 2 - 4 } & Multifocal clonic & 9 & 21.9 \\
\cline { 2 - 4 } & Tonic & 8 & 19.5 \\
\hline Seizures (single/multiple) & 41 & 68.3 \\
\hline \multicolumn{2}{|l|}{ Respiratory distress } & 32 & 53.3 \\
\hline Shock & 29 & 48.3 \\
\hline \multicolumn{2}{|l|}{ Congestive heart failure } & 1 & 1.7 \\
\hline \multicolumn{2}{|l}{ Full anterior fontanel } & 6 & 10.0 \\
\hline
\end{tabular}

Table 2: Biochemical profile of neonates with birth asphyxia

\begin{tabular}{|l|c|c|}
\hline \multicolumn{1}{|c|}{ Biochemical details } & $\mathbf{n}$ & $\%$ \\
\hline Hypocalcemia & 7 & 11.7 \\
\hline Hyponatremia & 14 & 23.3 \\
\hline Hypothermia & 3 & 5.0 \\
\hline Hyperbilirubinemia & 9 & 15.0 \\
\hline Acute renal failure & 20 & 33.3 \\
\hline Meconium aspiration syndrome & 8 & 13.3 \\
\hline Oliguria-day 1 & 35 & 58.3 \\
\hline Oliguria-day2 & 18 & 30.0 \\
\hline Oliguriat-day3 & 14 & 23.3 \\
\hline
\end{tabular}

Various clinical and biochemical parameters were analyzed in relation to HIE staging and observations are shown in Table 3. Seizures were present in 41(68.3\%) neonates; of these 27 in moderate whereas 14 cases in severe HIE had seizures (Fig.1). Seizures $(P<0,001)$, respiratory distress $(P=0.015)$ and shock $(P<0.001)$ were found to be highly significant among different HIE stages. Of various biochemical tests, serum creatinine was the only parameter which differed significantly $(\mathrm{P}=0.004)$ with maximum value in HIE stage III. Although the mean blood urea level was higher in severe stage in comparison to mild to moderate stages, but it failed to reach the level of statistical significance. 
Table 3: Clinical and biochemical parameters according to HIE staging

\begin{tabular}{|c|c|c|c|c|c|}
\hline \multirow[b]{2}{*}{ Parameters } & \multirow[b]{2}{*}{ Categories } & \multicolumn{3}{|c|}{ HIE Stages } & \multirow[b]{2}{*}{$\mathbf{P}$} \\
\hline & & $\begin{array}{c}\text { Mild } \\
n=13(\%)\end{array}$ & $\begin{array}{c}\text { Moderate } \\
\mathbf{n}=27(\%)\end{array}$ & $\begin{array}{c}\text { Severe } \\
n=20(\%)\end{array}$ & \\
\hline \multicolumn{2}{|l|}{ Seizures } & $0(0)$ & $27(45)$ & $14(55)$ & \multirow{7}{*}{$<0.001^{*}$} \\
\hline \multirow{6}{*}{ Types of seizures } & Subtle & $0(0)$ & $15(25)$ & $9(15)$ & \\
\hline & Subtle+clonic & $0(0)$ & $2(3.3)$ & $1(1.6)$ & \\
\hline & Subtle+tonic & $0(0)$ & $2(3.3)$ & $1(1.6)$ & \\
\hline & Multifocal Clonic & $0(0)$ & $5(8.3)$ & $1(1.6)$ & \\
\hline & Tonic & $0(0)$ & $2(3.3)$ & $2(3.3)$ & \\
\hline & Tonic+subtle & $0(0)$ & $1(1.6)$ & $0(0)$ & \\
\hline \multicolumn{2}{|c|}{ Respiratory distress } & $8(13.3)$ & $9(15)$. & $15(25)$ & $0.015^{*}$ \\
\hline \multicolumn{2}{|c|}{ Shock } & $0(0)$ & $9(15)$ & $20(33.3)$ & $<0.001^{*}$ \\
\hline \multicolumn{2}{|c|}{ Congestive heart failure } & $0(0)$ & $0(0)$ & $1(1.6)$ & $0.362^{*}$ \\
\hline \multicolumn{2}{|c|}{ Hypoglycemia } & $1(1.6)$ & $6(10)$ & $4(6.6)$ & $0.524^{*}$ \\
\hline \multicolumn{2}{|l|}{ Hematocrit (\%) } & $52.4 \pm 4.3$ & $47.9 \pm 7.5$ & $47.3 \pm 7.0$ & $0.097^{* *}$ \\
\hline \multicolumn{2}{|c|}{ Tolal leucocyte count $\left(\mathrm{mm}^{3}\right)$} & $16815.3 \pm 2927.9$ & $20081.4 \pm 7362.9$ & $20820 \pm 7130.8$ & $0.216^{* *}$ \\
\hline \multicolumn{2}{|c|}{ Urea $(\mathrm{mg} / \mathrm{dl})$} & $38 \pm 26.4$ & $31.9 \pm 16.0$ & $51.9 \pm 46.6$ & $0.105^{* * * *}$ \\
\hline \multicolumn{2}{|l|}{ Creatinine(mg/dl) } & $1.0 \pm 0.4$ & $1.1 \pm 0.4$ & $1.8 \pm 1.2$ & $0.004^{* * *}$ \\
\hline \multicolumn{2}{|l|}{$\mathrm{Na}(\mathrm{meq} / \mathrm{L})$} & $140.4 \pm 3.4$ & $138.7 \pm 6.5$ & $140 \pm 16.1$ & $0.855^{* *}$ \\
\hline \multicolumn{2}{|l|}{$\mathrm{K}(\mathrm{meq} / \mathrm{L})$} & $4.9 \pm 0.6$ & $5.0 \pm 0.6$ & $5.3 \pm 1.2$ & $0.49 * *$ \\
\hline \multicolumn{2}{|l|}{ Calcium(mg/dl) } & $1.1 \pm 0.1$ & $1.5 \pm 0.1$ & $1.1 \pm 0.1$ & $0.606^{* *}$ \\
\hline \multicolumn{2}{|c|}{ Blood sugar(mg/dl) } & $84.1 \pm 26.0$ & $87.2 \pm 54.2$ & $92.7 \pm 46.6$ & $0.864^{* * *}$ \\
\hline
\end{tabular}

\section{Discussion}

The higher neonatal mortality rate due to various causes is a major concern among all health professionals in Nepal. Birth asphyxia is a significant contributory factor as most of the deliveries are conducted by untrained personnels and that too in rural and hilly areas. By the time a sick neonates arrive at a tertiary care center, the babies have already progressed to various stages HIE with multi organ dysfunctions. This is clearly evident that $47 / 60(78.3 \%)$ neonates in our study had moderate to severe grades of HIE. Majeed et al..$^{14}$ reported moderate to severe $\mathrm{HIE}$ in $28 \%$, mild in $36 \%$ and no $\mathrm{HIE}$ in $34 \%$ of their cases. The difference of our findings from this study is because of the fact that we had included only those cases of birth asphyxia that developed HIE. The development of cardiac complications in asphyxiated neonates is due to hypoxic injury to myocardium. The most common feature was respiratory distress present in 32 (53.3\%) and shock was present in 29 (48.3\%). The predominant features of cardiac dysfunction were respiratory distress (53.3\%), shock (48.3\%) and congestive heart failure $9(1.7 \%)$ in our study. Rajakumar et $\mathrm{al}^{4}$ found respiratory distress (66.7\%), cardiac failure $(36.7 \%)$ and cardiogenic shock in $5(16.7 \%)$ neonates in their study. The proportion of neonates having shock in our study is comparable with the finding of Mandal et al $(44 \%)^{15}$
Respiratory distress could be mainly due to meconium aspiration syndrome and/or brain edema. Seizures were noted in $68.3 \%$ of cases and were mainly due to brain edema, birth trauma and metabolic complications. Among various metabolic changes, hyponatremia, hypocalcemia and hypoglycemia were major alterations seen in our study. Kumar et $\mathrm{al}^{16}$ also found these abnormalities in $37.5 \%, 12.5 \%$ and $25 \%$ of their cases with birth asphyxia and emphasized the fact that these factors are often the causes of seizures in these cases.

Further, it was found that seizures, respiratory distress and shock had significant associations with increasing severity of HIE stages. Hyperbilirubinemia was seen in $15 \%$ of neonates and birth asphyxia per se is an independent risk factor for development of jaundice ${ }^{17}$. Thus, it is evident that multi- organ involvement mainly in moderate to severe grades of HIE complicates the clinical course of these neonates requiring NICU admission. Hypoxic injury to kidney is another complication which poses further problem and found in $33 \%$ of neonates and showed increasing in severity with increasing grades of HIE. Serum creatinine differed significantly among different grades of HIE with higher values in moderate and severe stages. Gupta et al. (18) reported acute renal failure in 33 (47.1\%) cases, 
of which non-oliguric type in $78 \%$ and oliguric type in $22 \%$ cases. Oliguria was present in $14(23.3 \%)$ patients after 72 hours of postnatal age. However, all our cases improved with supportive treatment and none required peritoneal dialysis or exchange transfusion.

\section{Conclusions}

The birth asphyxia is the leading cause of neonatal morbidity, mortality and NICU admissions in developing countries. Neonates with HIE develop multi-organ dysfunctions which can be diagnosed by clinical and biochemical alterations. Early detection of multiorgan dysfunction helps in intensive monitoring and appropriate management so that their outcome can be further improved.

\section{Acknowledgements: None \\ Funding: None \\ Conflict of Interest: Nil \\ Permission from IRB: Yes}

\section{References}

1. Adcock LM, Papile LA. Perinatal asphyxia. In: Cloherty JP, Eichenwald EC, Stark AR, editor. Manual of neonatal care. 6th ed.New Delhi:Wolters Kluwer;2008.p.518-523.

2. Flores-Nava G, Echevarría-Ybarguengoitia JL, Navarro-Barrón JL, García-Alonso A. Isquemia miocárdica transitoria en el recién nacido con asfixia perinatal (miocardiopatía hipóxica). Bol Med Hosp Infant Mex 1990;47:809.

3. Rowe RD, Hoffman T. Transient myocardial ischemia of the newborn infant: a form of severe cardiorespiratory distress in full-term infants. J Pediatrics 1972; 28:243-245.

4. Rajakumar PS, Bhat BV, Sridhar MG, Balachander J, Konar BC, Narayanan P and Chetan G. Cardiac enzyme levels in myocardial dysfunction in newborns with perinatal asphyxia. Indian J Pediatr 2008; 75 (12): 1223-1225.

5. Costello AM de L Perinatal health in developing countries. Trans R Soc Trop Med Hyg 1993; 87: 1-2.

6. World Health Organisation. Child health and development: health of the newborn. Geneva: World Health Organisation, 1991.
7. Agarwal R, Jain A, Deorari AK, Paul VK. Postresuscitation management of asphyxiated neonates. Indian J of Paediatr 2008;75:85-90.

8. Fernández-Carrocera LA, Flores-Tamez E, SalinasRamírez V, Bravo-Cabrera Z, Venta-Sobero JA, Udaeta-Mora E, Ugartechea HJC, Lozano-González $\mathrm{CH}$. El puntaje de Apgar como predictor de secuelas neurológicas. Bol Med Hosp Infant Mex 1989;46:554.

9. Committee on Fetus and Newborn (1985-1986). Use and abuse of the Apgar score. Pediatrics 1986;78:1148.

10. Haidary MH, Hussain A, Ahmed S, Abul Kasem A. Clinical profile of birth asphyxia in Rajshahi Medical College Hospital. TAJ 2005; 18(2): 106-108.

11. Martín-Ancel A, García-Alix A, Gayá Fernando Cabañas F, Burgueros M,Quero J. Multiple organ involvement in perinatal asphyxia. J Pediatr 1995;127:786-793.

12. Perlman JM, Risser R. Can asphyxiated infants at risk for neonatal seizures be rapidly identified by current high-risk markers? Pediatrics. 1996 Apr;97(4): 456-62.

13. Levene MI. The asphyxiated newborn infant. In: Levene MI, Lilford RJ. Fetal and neonatal neurology and neuro-surgary. Edinburgh: Churchil Livingstone 1995: 405- 426.

14. Majeed R, Memon Y, Majeed F, Naheed Parveen Shaikh NP, Rajar UDM. Risk factors of birth asphyxia. J Ayub Med Coll Abbottabad 2007; 19: 67-71.

15. Mandal RN, Gupta R, Kapoor AK. Evaluation of activity of creatine phosphokinase (CPK) and its isoenzyme CPK-MB in perinatal asphyxia and its implications for myocardial involvement. Bull NNF $1999 ; 13: 2-7$.

16. Kumar A, Gupta V, Kachhawaha, Singla PN. Biochemical changes in neonatal seizures. Indian Pediatr1995; 32: 424-428.

17. Arif $K$, Bhutta ZA. Risk Factors and spectrum of neonatal jaundice in a birth cohort in Karachi. Indian Pediatr 1999; 36:487-493.

18. Gupta BD, Sharma P, Bagla J, Parakh M, Soni JP. Renal failure in asphyxiated Neonates. Indian Pediatr. 2005 Sep; 42:928-34.

\section{How to cite this article?}

Shah GS, Agrawal J, Mishra OP, Chalise S. Clinico- Biochemical Profile of Neonates with Birth Asphyxia in Eastern Nepal. J Nepal Paediatr Soc 2012;32(3):206-209. 